\title{
Glycemia and the quality of well-being in patients with diabetes
}

\author{
B.P. Tabaei ${ }^{1}$, J. Shill-Novak ${ }^{1}$, M. Brandle ${ }^{1}$, R. Burke ${ }^{1}$, R.M. Kaplan ${ }^{4}$ \& W.H. Herman ${ }^{1,2,3}$ \\ ${ }^{1}$ Division of Endocrinology \& Metabolism, Department of Internal Medicine; ${ }^{2}$ Department of Epidemiology; \\ ${ }^{3}$ Michigan Diabetes Research and Training Center, University of Michigan, Ann Arbor, MI (E-mail: \\ wherman@umich.edu); ${ }^{4}$ Department of Community Medicine, University of California at San Diego, CA, USA
}

Accepted in revised form 6 August 2003

\begin{abstract}
Objectives: To investigate the cross-sectional relationships among self-reported frequencies of symptomatic hyperglycemia and hypoglycemia, HbAlc, and symptoms in the Quality of Well-Being Self-Administered (QWB-SA), and to examine the associations among these measures of glycemia and health-utility scores. Methods: The study group included 1522 patients with diabetes who attended University of Michigan Health System clinics. Published studies were reviewed to identify symptoms in the QWB-SA that might be associated with measures of glycemia. Linear-regression analyses were performed to evaluate the strength of the associations among the frequency of self-reported measures of glycemia, QWB-SA symptoms, and QWB-SA-derived health-utility scores. Results: Frequency of hyperglycemic symptoms was associated with $3 \%$ of the variance in the QWB-SA-derived health-utility score in type-1 diabetes and with $5 \%$ of the variance in type-2 diabetes. Frequency of hypoglycemic symptoms was not associated with the QWB-SAderived health-utility score in type- 1 diabetes but was associated with $1 \%$ of the variance in type- 2 diabetes. HbA1c levels were not significantly associated with QWB-SA-derived health-utility scores. After controlling for age, gender, and complications, frequency of hyperglycemic symptoms was significantly associated with QWB-SA-derived health-utility scores in type-1 and type-2 diabetes. Conclusions: Reported frequency of hyperglycemic symptoms is associated with symptoms included in the QWB-SA and with QWB-SAderived health-utility scores. The QWB-SA may be an appropriate measure to assess the health burden of hyperglycemia.
\end{abstract}

Key words: Clinical economics, Cost-effectiveness, Diabetes mellitus, Health utilities, Hemoglobin A1c, Hyperglycemia, Hypoglycemia, Quality-adjusted life-years

\section{Introduction}

In recent years, the relationship between glycemic control and quality of life (QoL) has been studied in patients with diabetes by applying disease-specific and generic QoL instruments. Studies that used disease-specific instruments have reported associations between glycemic control and QoL [1, 2] as have some studies that used generic instruments $[3,4]$. To date, however, only one study has employed multiattribute utility models or assessed the relationship between glycemic control and health-utility scores [5]. Since the Self-Adminis- tered Quality of Well-Being questionnaire (QWBSA) contains questions about symptoms that potentially reflect changes in glycemia, we used the QWB-SA to explore the relationship between measures of glycemia, assessed as self-reported frequencies of symptomatic hyperglycemia and hypoglycemia, and HbAlc, and health-utility scores.

Previously, we have shown that major diabetes complications are associated with lower healthutility scores [6]. Our current study involved four questions: first, which symptoms in the QWB-SA are most strongly associated with measures of 
glycemia (self-reported frequencies of symptomatic hyperglycemia and hypoglycemia, and HbA1c) in patients with diabetes? Second, is the QWB-SA-derived health-utility score associated with measures of glycemia in diabetic patients? Third, to what extent does the QWB-SA-derived health-utility score in diabetic patients vary with age, gender and complications. Fourth, is the QWB-SA-derived health-utility score associated with measures of glycemia in diabetic patients when age, gender and complications are also considered?

\section{Methods}

The QWB-SA was developed in 1996 as a selfadministered, scanable version of the Quality of Wellbeing Index (QWB), a previously validated measure of preference-based general health status $[7,8]$ that has been used in populations with a variety of diseases [1, 9, 11-18]. The QWB-SA assesses symptoms (acute and chronic) and functioning (self-care, mobility, physical activity, and social activity) to provide a health-utility score as a summary measure of QoL $[9,10]$. The worst symptom for each of the four domains for each day (yesterday, two days ago, three days ago) enters into the scoring system. The symptoms and reported levels of functioning are weighted by the preferences of an independent sample of judges. Using this system, it is possible to place the general health status of any individual on the continuum between death and optimal functioning. The QWB-SA has been shown to be highly correlated with and to retain the psychometric properties of the QWB [12].

The protocol was reviewed and approved by the University of Michigan Institutional Review Board and all patients provided written informed consent. We estimated that to detect a clinically meaningful difference of 0.025 in the QWB-derived health-utility score [19] with $90 \%$ power and $\alpha=0.05$, we would need to study approximately 600 patients with type- 1 diabetes and 600 patients with type-2 diabetes. The study group included 1522 patients: 634 with type- 1 diabetes and 888 with type- 2 diabetes who attended endocrinology, diabetes, and ophthalmology clinics at the University of Michigan Health System between June
29, 1998 and March 15, 2001 and had HbAlc measurements on the day of the visit. All patients were $\geqslant 18$ years of age, able to give informed consent, and able to either self-administer the questionnaires or, if visually impaired, to respond to a research assistant reading the questionnaires.

The questionnaires used were the Diabetes Staging Questionnaire (DSQ) and the QWB-SA. The DSQ was adapted from two instruments available from the Michigan Diabetes Research and Training Center, the Diabetes Care Profile (DCP) and the Diabetes Medical History (DMH). The DCP is a validated instrument $[20,21]$ which includes questions about demographics, age at onset of diabetes, frequency of hyperglycemic and hypoglycemic symptoms, and limits on performing activities of daily living due to diabetes. Frequency of symptomatic hyperglycemia was self-reported as the number of times in the past month the patient experienced high blood sugar with symptoms such as thirst, dry mouth and skin, increased sugar in the urine, less appetite, nausea or fatigue. Frequency of symptomatic hypoglycemia was self-reported as the number of times in the past month the patient experienced a low blood-sugar reaction with symptoms such as sweating, weakness, anxiety, trembling, hunger or headache. The DCP subscale on control problems, which included questions on the frequency of hyperglycemic and hypoglycemic symptoms, is reliable (Cronbach's $\alpha=0.86)$ and correlated with glycosylated hemoglobin level $(r=0.21, p<0.01)$ [21]. The subscale on control problems is also significantly associated with the Centers for Epidemiologic Studies depression scale $(r=0.34, p \leqslant 0.01)$ [21]. Type- 1 diabetes was defined as diabetes with onset before 30 years of age with current insulin treatment. Type-2 diabetes was defined as diabetes with onset at 30 years of age or older with diet, oral agent or insulin treatment, or diabetes with onset before 30 years of age without current insulin treatment. HbAlc was measured using capillary blood and a Bayer DCA 2000 analyzer (Bayer, Elkhart, Indiana). Quality control procedures included daily assays on standard normal and abnormal control samples containing a stable lyophilized hemolysate of human blood. Patient samples were not run until acceptable quality control results were achieved. Coefficients of variation were $<5 \%$ (STAT Technologies, Golden Valley, Minnesota). 
Correlation of DCA readings and high performance liquid chromotography (HPLC) measures of HbAlc is 0.99 .

Descriptive statistics were obtained for all variables using medians and minimums and maximums for continuous variables, and frequencies and proportions for categorical variables. Statistical significance of differences between groups was assessed with the Wilcoxon rank sum test for continuous variables and the Cochran-MantelHaenszel $\chi^{2}$ test for categorical variables (Table 1).

To identify which symptoms in the QWB-SA were most strongly associated with measures of glycemia, we reviewed published studies relating symptoms to glycemic control. Grootenhuis et al. [22] developed a Diabetes Symptom Checklist for type-2 Diabetes (DSC-Type 2) that included symptoms related to hyperglycemia and hypoglycemia. Testa and Simonson also provided a list of symptoms affected by improved glycemic control [23]. Based on these studies, we selected 14 symptoms (8 hyperglycemic, 9 hypoglycemic, and 3 shared symptoms) from the QWB-SA questionnaire. The responses to these 14 symptom questions from the QWB-SA were compared with the self-reported frequency of hyperglycemia and hypoglycemia and with $\mathrm{HbAlc}$ values. Each measure of glycemia was divided into five groups. For the frequency of hyperglycemic and hypoglycemic symptoms reported within the past month, categories were 0 times, 1-4 times, 5-8 times, 9-12 times, and over 12 times. HbAlc values were distributed into 5 equal groups that differed by type of diabetes, varying from less than $7.0 \%$ to more than $9.6 \%$.

The relationship between individual QWB-SA symptoms and measures of glycemia (reported frequency of hyperglycemia and hypoglycemia, and measured HbAlc categories) were assessed with one-way analysis of variance using general linear models (Table 2). Relationships among health-utility scores and measures of glycemia were assessed with one-way analysis of variance using general linear models (Figure 1) and simple linear regression analysis (Table 3, panel A). To further evaluate the strength of the associations between the QWB-SA-derived utility scores and the predictor variables, multiple linear regression analysis was performed (Table 3, panel B). For both types of diabetes, linear regression models

Table 1. Characteristics and comparison of study group by type of diabetes

\begin{tabular}{|c|c|c|}
\hline Characteristics & Type-1 diabetes & Type-2 diabetes \\
\hline Total number & 634 & 888 \\
\hline Age, median (min.-max.), years & $33(18-78)$ & $56(18-88)^{*}$ \\
\hline Female gender $(\%)$ & 54 & $48^{* *}$ \\
\hline White $(\%)$ & 86 & $74 * * *$ \\
\hline BMI, median (min. - max.), $\mathrm{kg} / \mathrm{m}^{2}$ & $25(15-70)$ & $31(16-66)$ \\
\hline Duration of diabetes, median (min.-max.), years & $19(0-77)$ & $9(0-61)^{*}$ \\
\hline Diabetes treatment $(\%)$, insulin $/ \mathrm{OHA} /$ diet & $100 / 0 / 0$ & $54 / 39 / 7 *$ \\
\hline$>4$ Hyperglycemic episodes per month $(\%)$ & 22 & 25 \\
\hline$>4$ Hypoglycemic episodes per month $(\%)$ & 13 & $8 * * *$ \\
\hline HbAlc, median (min.-max.) & $8.3(4.7-14.1)$ & $8.0(4.1-14.0)^{* *}$ \\
\hline Retinopathy $(\%)$ & 38 & $22 *$ \\
\hline Nephropathy (\%) & 26 & $19^{*}$ \\
\hline Renal transplant (\%) & 4 & $1 *$ \\
\hline Neuropathy $(\%)$ & 30 & $45^{*}$ \\
\hline Amputation $(\%)$ & 2 & 2 \\
\hline Hypertension (\%) & 33 & $59 *$ \\
\hline Hypercholesterolemia (\%) & 29 & $60^{*}$ \\
\hline Smoker $(\%)$ & 24 & $13^{*}$ \\
\hline Stroke $(\%)$ & 2 & 3 \\
\hline Limitations due to heart disease $(\%)$ & 9 & $27 *$ \\
\hline Peripheral vascular disease $(\%)$ & 11 & $16^{* * *}$ \\
\hline
\end{tabular}

$\mathrm{BMI}=$ body mass index [weight $(\mathrm{kg}) /$ height $\left.\left(\mathrm{m}^{2}\right)\right]$, OHA $=$ oral hypoglycemic agents; HbAlc $=$ glycosylated hemoglobin. $* p<0.001, * * p<0.05, * * * p<0.01$, statistically significance difference type-1 vs. type-2 diabetes patients. 
Table 2. Relationship between QWB-SA symptoms and measures of glycemia

\begin{tabular}{|c|c|c|c|c|}
\hline & \multicolumn{2}{|c|}{ Type-1 diabetes } & \multicolumn{2}{|c|}{ Type-2 diabetes } \\
\hline & $R^{2}$ & $p$-Value* & $R^{2}$ & $p$-Value* \\
\hline \multicolumn{5}{|l|}{ Frequency of hyperglycemic symptoms } \\
\hline Current general fatigue, tiredness, weakness & 0.052 & 0.0001 & 0.051 & 0.0001 \\
\hline $\begin{array}{l}\text { Loss of bladder control, frequent night-time } \\
\text { urination, difficulty with urination }\end{array}$ & 0.036 & 0.0001 & 0.051 & 0.0001 \\
\hline Loss of appetite, over-eating & 0.030 & 0.005 & 0.035 & 0.0001 \\
\hline Current unwanted weight gain or loss & 0.025 & 0.01 & 0.011 & 0.10 \\
\hline Headache & 0.015 & 0.19 & 0.032 & 0.0009 \\
\hline Genital pain, itching, burning, abnormal discharge, pelvic cramping, abnormal bleeding & 0.009 & 0.26 & 0.039 & 0.002 \\
\hline Upset stomach, abdominal pain, nausea, heartburn or vomiting & 0.009 & 0.33 & 0.029 & 0.002 \\
\hline \multicolumn{5}{|l|}{ Frequency of hypoglycemic symptoms } \\
\hline Headache & 0.023 & 0.005 & 0.020 & 0.002 \\
\hline Fever, chills or sweats & 0.013 & 0.06 & 0.031 & 0.02 \\
\hline Spells of feeling nervous or shaky & 0.009 & 0.18 & 0.064 & 0.0001 \\
\hline Current general fatigue, tiredness, weakness & 0.004 & 0.41 & 0.013 & 0.03 \\
\hline Excessive anxiety or worry & 0.002 & 0.86 & 0.019 & 0.003 \\
\hline \multicolumn{5}{|l|}{ HbAlc level } \\
\hline Genital pain, itching, burning, abnormal discharge/bleeding, pelvic cramping & 0.023 & 0.0008 & 0.002 & 0.78 \\
\hline Loss of bladder control, frequent night-time urination, difficulty with urination & 0.021 & 0.02 & 0.014 & 0.02 \\
\hline Fever, chills or sweats & 0.017 & 0.03 & 0.006 & 0.30 \\
\hline
\end{tabular}

* The coefficients of determinations $\left(R^{2}\right)$ and $p$-values were generated from the analysis of variance using general linear models and show the degree of general association between the measures of glycemia and QWB-SA symptoms. The measures of glycemia were modeled as categorical variables.

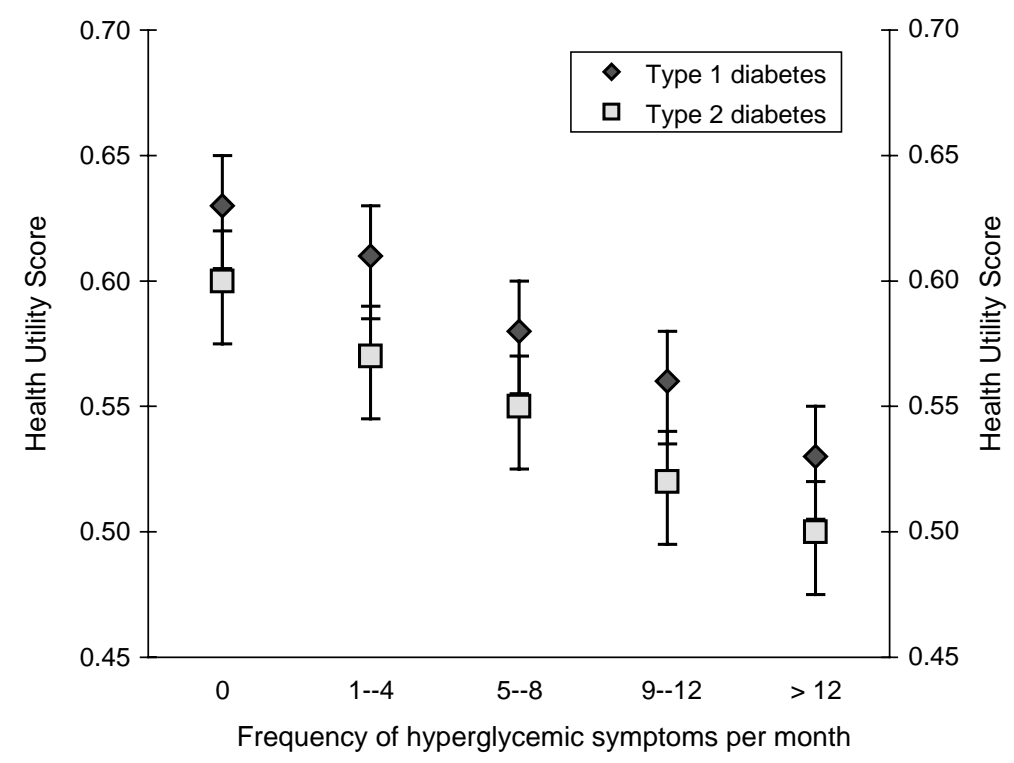

Figure 1. Frequency of self-reported hyperglycemic symptoms and mean $(95 \%$ CIs) total QWB-SA-derived health utility scores in type- 1 and type- 2 diabetic patients. 
Table 3. Overall QWB-SA score, regression coefficient, and correlation coefficient by type of diabetes and (A) measures of glycemia, (B) sex and complications controlling for age, (C) frequency of hyperglycemic symptoms, sex, and complications controlling for age

\begin{tabular}{|c|c|c|c|c|}
\hline \multirow[t]{2}{*}{ Mean QWB-SA score } & \multicolumn{2}{|c|}{ Type-1 diabetes $(0.63)$} & \multicolumn{2}{|c|}{ Type-2 diabetes $(0.60)$} \\
\hline & $\begin{array}{l}\text { Regression } \\
\text { coefficient (SE) }\end{array}$ & $\begin{array}{l}\text { Correlation } \\
\text { coefficient }\end{array}$ & $\begin{array}{l}\text { Regression } \\
\text { coefficient (SE) }\end{array}$ & $\begin{array}{l}\text { Correlation } \\
\text { coefficient }\end{array}$ \\
\hline \multicolumn{5}{|l|}{ Panel $A$} \\
\hline $\begin{array}{l}\text { Frequency of hyperglycemic } \\
\text { symptoms by group }(0,1-4,5-8,9-12,12+)\end{array}$ & $-0.025(0.005)^{*}$ & $-0.184^{*}$ & $-0.026(0.004)^{*}$ & $0.220 *$ \\
\hline $\begin{array}{l}\text { Frequency of hypoglycemic } \\
\text { symptoms by group }(0,1-4,5-8,9+)\end{array}$ & $-0.010(0.006)$ & -0.060 & $-0.019(0.006)^{*}$ & $0.001 *$ \\
\hline HbA1c level by group & $-0.006(0.004)$ & -0.066 & $-0.004(0.003)$ & -0.042 \\
\hline \multicolumn{5}{|l|}{ Panel B } \\
\hline Female gender & $-0.044(0.012)^{*}$ & $-0.148^{*}$ & $-0.027(0.001)^{* *}$ & $-0.098 * *$ \\
\hline Neuropathy & $-0.074(0.013)^{*}$ & $-0.207 *$ & $-0.072(0.010)^{*}$ & $-0.240 *$ \\
\hline Amputation & - & - & $-0.114(0.034)^{*}$ & $-0.112^{*}$ \\
\hline Blindness & $-0.128(0.016)^{*}$ & $-0.302 *$ & $-0.109(0.012)^{*}$ & $-0.295^{*}$ \\
\hline Hypertension & $-0.060(0.014)^{*}$ & $-0.164 *$ & $-0.022(0.010)^{* * *}$ & $-0.073 * * *$ \\
\hline Stroke & $-0.115(0.045)$ & $-0.097^{*}$ & $-0.087(0.028)^{*}$ & $-0.102 * *$ \\
\hline Peripheral vascular disease & $-0.080(0.019)^{*}$ & $-0.163^{*}$ & $-0.112(0.014)^{*}$ & $-0.271 *$ \\
\hline Limitations due to heart disease & - & -0.060 & $-0.027(0.011)^{* * *}$ & $-0.074 * * *$ \\
\hline \multicolumn{5}{|l|}{ Panel $C$} \\
\hline $\begin{array}{l}\text { Frequency of hyperglycemic } \\
\text { symptoms by group }(0,1-4,5-8,9-12,12+)\end{array}$ & $-0.020(0.005)^{*}$ & $-0.177^{*}$ & $-0.018(0.003)^{*}$ & $-0.181^{*}$ \\
\hline Female gender & $-0.040(0.012)^{*}$ & $-0.136^{*}$ & $-0.031(0.010)^{*}$ & $-0.110^{*}$ \\
\hline Neuropathy & $-0.068(0.014)^{*}$ & $-0.196^{*}$ & $-0.077(0.010)^{*}$ & $-0.256^{*}$ \\
\hline Amputation & - & - & $-0.131(0.034)^{*}$ & $-0.135^{*}$ \\
\hline Blindness & $-0.132(0.016)^{*}$ & $-0.312 *$ & $-0.109(0.012)^{*}$ & $-0.306^{*}$ \\
\hline Hypertension & $-0.056(0.014)^{*}$ & $-0.165^{*}$ & $-0.014(0.010)$ & -0.486 \\
\hline Stroke & $-0.121(0.045)^{* *}$ & $-0.108^{*}$ & $-0.082(0.027)^{* *}$ & $-0.107 * *$ \\
\hline Peripheral vascular disease & $-0.080(0.020)^{*}$ & $-0.161 *$ & $-0.101(0.014)^{*}$ & $-0.246^{*}$ \\
\hline Limitations due to heart disease & - & - & $-0.026(0.012)^{* * *}$ & $-0.079 * * *$ \\
\hline
\end{tabular}

$\mathrm{SE}=$ Standard error of the coefficient; $-=$ not computed.

${ }^{*} p<0.001, * * p<0.01, * * * p<0.05$.

were developed and fitted to the data using the forward stepwise selection procedure with the QWB-SA-derived utility scores as the dependent variable and age, sex, duration of diabetes and the complications of diabetes as independent covariates. Once the influence of age, gender, duration of diabetes, and diabetic complications was determined, the influence of frequency of hyperglycemic and hypoglycemic symptoms and HbAlc on the QWB-SA-derived utility score was evaluated by forcing individual measures of glycemia into these stepwise-selected linear regression models (Table 3, panel C).

Because the QWB-SA-derived health-utility scores varied from 0 to 1.0 , and were not normally distributed, we empirically transformed them us- ing $\arcsin \left(\sin ^{-1}\right)$ in the linear analysis (both Pearson correlations and linear regressions) presented in Table 3 [24, 25]. Interaction terms between independent variables were also considered. None of the interaction effects were statistically significant. The coefficient of determination $\left(R^{2}\right)$ was used as a quantitative measure of how well the independent variables explain the outcome. For the multiple linear regression models, adjusted $R^{2}$ was used to control for the number of independent variables in the equation. Pearson correlation analysis and partial correlation analysis were performed to assess the strength of the relationship between the outcome variable (QWB-SA-derived utility score) and the independent variables in the linear regression models. A $p$-value $<0.05$ was 
defined as statistically significant. All statistical analyses were performed using SAS software version 6.12 (SAS Institute, Cary, North Carolina).

\section{Results}

Table 1 describes the clinical and demographic characteristics of the patients by type of diabetes. In general, patients with type-1 diabetes were more likely to be younger, female, white, and to have longer duration of diabetes than patients with type-2 diabetes. More than one-half of patients with type-2 diabetes were treated with insulin. Frequency of more than four hyperglycemic episodes in the past month did not differ among patients with type- 1 and type- 2 diabetes. However, $13 \%$ of type- 1 diabetic patients experienced more than four hypoglycemic episodes in the past month compared to $8 \%$ of patients with type- 2 diabetes. The median HbAlc was significantly higher for type-1 diabetic patients. Retinopathy, laser treatment, nephropathy, renal transplant, and smoking were more common in patients with type- 1 diabetes. Patients with type- 2 diabetes were more likely to have neuropathy, hypertension, hypercholesterolemia, and limitations due to heart disease and peripheral vascular disease.

Table 2 presents the relationship among QWBSA symptoms and the frequency of self-reported hyperglycemic and hypoglycemic symptoms over the past month, and HbAlc. In both type-1 and -2 diabetic patients, QWB-SA symptoms related to lack of energy, headache, appetite and abnormal urination were positively associated with the selfreported frequency of hyperglycemia. Headache was positively associated with self-reported frequency of hypoglycemia. Abnormal urination was positively associated with HbAlc. Among patients with type-1 diabetes, weight changes were positively associated with the self-reported frequency of hyperglycemia, and sweating and genital symptoms were positively associated with HbA1c. Among patients with type-2 diabetes, upper gastrointestinal discomfort and genital problems were positively associated with the selfreported frequency of hyperglycemia. Lack of energy, anxiety, nervousness and sweating were positively associated with the self-reported fre- quency of hypoglycemia. In patients with type-2 diabetes, symptoms were for the most part associated with measures of glycemia per se and not with specific diabetes treatments (data not shown).

Figure 1 presents the frequency of self-reported hyperglycemic symptoms per month and mean total QWB-SA-derived health-utility scores by type of diabetes. Mean (95\% CI) QWB-SA-derived health-utility scores for type-1 and type-2 diabetes patients with no hyperglycemic symptoms were $0.63(0.61-0.65)$ and $0.60(0.57-0.63)$, with 1-4 hyperglycemic symptoms were $0.61(0.58$ $0.63)$ and $0.57(0.55-0.59)$, with $5-8$ hyperglycemic symptoms were $0.58(0.56-0.60)$ and $0.55(0.52$ 0.58 ), with 9-12 hyperglycemic symptoms were $0.56(0.54-0.57)$ and $0.52(0.49-0.55)$, and with $>12$ hyperglycemic symptoms were 0.53 $(0.50-0.55)$ and $0.50(0.47-0.53)$, respectively. In both type-1 and type-2 diabetic, patients with more frequent hyperglycemic symptoms had lower health-utility scores $(p=0.003$ and $p=0.0001$ respectively). Hyperglycemic symptoms were associated with $3 \%$ of the variance in the utility score in type- 1 diabetic patients $\left(R^{2}=0.03, p=0.0001\right)$, and with $5 \%$ of the variance in type- 2 diabetic patients $\left(R^{2}=0.05, p=0.0001\right)$ (Table 3 , panel A). Hyperglycemic symptoms were negatively correlated with QWB-SA-derived utility scores in type-1 diabetic patients (correlation $=-0.184$, $p=0.0001)$ and type-2 diabetic patients (correlation $=-0.220, p=0.0001)$. Compared to patients with no episodes of hyperglycemic symptoms, frequency of hyperglycemic symptoms was associated with a reduction in health-utility score of $0.025,0.050,0.075$, and 0.10 in type- 1 diabetic patients and $0.026,0.052,0.078$, and 0.104 in type2 diabetes patients with $1-4,5-8,9-12$, and $12+$ episodes of hyperglycemic symptoms over the past month.

Frequency of self-reported hypoglycemic symptoms was not significantly related to the QWB-SAderived utility score in type-1 diabetic patients ( $p=0.66)$ but was inversely related to the total QWB-SA-derived utility score in type-2 diabetic patients $(p=0.004)$. Hypoglycemic symptoms were associated with $0.4 \%$ of the variance in the QWB-SA derived utility score in type-1 diabetic patients $\left(R^{2}=0.004, p=0.13\right)$, and with $1 \%$ of the variance in type- 2 diabetic patients $\left(R^{2}=0.01\right.$, 
$p=0.001)$. Hypoglycemic symptoms were not significantly correlated with QWB-SA-derived utility scores in type-1 diabetic patients (correlation $=-0.060, \quad p=0.13$ ) and only weakly negatively correlated with the utility score in type2 diabetic patients (correlation $=-0.113, p=$ 0.001). Compared to patients with no episodes of hypoglycemic symptoms, frequency of hypoglycemic symptoms was associated with a reduction in health-utility score of $0.019,0.038,0.057$, and 0.076 in type- 2 diabetic patients with $1-4,5-8,9$ 12 , and $12+$ episodes of hypoglycemic symptoms over the past month.

HbAlc was not significantly associated with the QWB-SA-derived utility score in type-1 or type-2 diabetic patients.

Gender differences and presence vs. absence of complications were responsible for $34 \%$ of the variance in the utility score in the patients with type-1 diabetes (adjusted $R^{2}=0.34, p=0.0001$ ) and $32 \%$ of the variance in type- 2 diabetic patients (adjusted $R^{2}=0.32, p=0.0001$ ) (Table 3 , panel B). When we forced measures of glycemia into the multivariable models after including gender and complications, frequency of hyperglycemic symptoms was negatively associated with the QWB-SAderived utility score and was responsible for $3 \%$ of the variance in the utility score in patients with both type- 1 and type- 2 diabetes (partial $R^{2}=0.03$, $p=0.0001$ ) (Table 3, panel C). Frequency of hyperglycemic symptoms was negatively correlated with QWB-SA-derived utility score in type-1 diabetic patients (partial correlation $=-0.177$, $p=0.0001$ ) and type-2 diabetic patients (partial correlation $=-0.181, p=0.0001$ ). Compared to patients with no episodes of hyperglycemic symptoms, frequency of hyperglycemic symptoms was associated with a reduction in health-utility score of $0.020,0.040,0.060$, and 0.080 in type- 1 diabetic patients and $0.018,0.036,0.054$, and 0.072 in type2 diabetes patients with $1-4,5-8,9-12$, and $12+$ episodes of hyperglycemic symptoms over the past month. Neither frequency of hypoglycemic symptoms nor $\mathrm{HbAlc}$ level was significantly associated with the health-utility score. (For type-1 diabetic patients, hypoglycemia, partial $R^{2}=-0.04$, $p=0.37$; HbAlc, partial $R^{2}=-0.05, p=0.25$; for type-2 diabetic patients, hypoglycemia, partial $R^{2}=-0.05, p=0.14$; HbAlc, partial $R^{2}=-0.02$, $p=0.55$.)

\section{Discussion}

QoL may be assessed using disease-specific and generic instruments. Disease-specific instruments focus on symptoms, function, and disability specific to particular diseases. Their disadvantage is that they are not comprehensive and cannot be used to compare QoL across different disease states. Generic instruments are designed for use in diverse disease states and across populations, but may not reflect small but clinically important disease-specific symptoms or changes in function [1, 20, 26].

The goal of our study was to determine the cross-sectional relationships among self-reported frequencies of symptomatic hyperglycemia and hypoglycemia and measured HbAlc and symptoms in the QWB-SA, and to assess the associations among these measures of glycemia in diabetic patients and health-utility scores. To our knowledge, this is the first study that has assessed the association between measures of glycemia and health utilities in type- 1 and type- 2 diabetic patients.

We demonstrated that the QWB-SA includes symptoms that are associated with measures of glycemia. QWB-SA symptoms related to lack of energy, headache, altered appetite, and abnormal urination were positively associated with the selfreported frequency of hyperglycemic symptoms in both type- 1 and type- 2 diabetic patients. In both type-1 and type-2 diabetic patients, headache was positively associated with frequency of hypoglycemic symptoms and urinary symptoms were associated with $\mathrm{HbAlc}$ levels.

The QWB-SA-derived health-utility score was negatively associated with the self-reported frequency of hyperglycemic symptoms in both type-1 and type-2 diabetic patients and the frequency of hyperglycemic symptoms explained $3-5 \%$ of the variance in the utility score (Table 3 , panel A). These results confirm studies showing a relationship between self-reported frequency of hyperglycemia and reduced treatment satisfaction as assessed by a disease-specific questionnaire [27]. The QWB-SA-derived health-utility score was also negatively associated with the frequency of hypoglycemic symptoms in type-2 diabetic patients, but explained less than $1 \%$ of the variance. Another study has shown a weak association between the 
frequency of hypoglycemic reactions and the physical role subscale of the SF-36 in patients with type-1 diabetes [3].

We found no association between QWB-SAderived health-utility scores and HbA1c. Several other studies that employed the SF-20 and SF-36 have also not demonstrated associations between QoL and HbA1c [2, 20, 28-30]. In contrast, a study that assessed QoL with a diabetes-specific measure [27], two studies that assessed QoL with the SF-36 and SWEDQUAL instruments [3, 4], and a study that assessed QoL with the EQ-5D [5] demonstrated relationships between QoL and HbA1c. The lack of association in our study may be explained in part by the generally good glycemic control and narrow range of HbAlc levels observed (fewer than $10 \%$ of patients with diabetes had HbAlc levels $>11 \%$ ).

Our results are consistent with other studies that have demonstrated lower health-utility scores in women with diabetes [6, 31-33] and worse QoL in the presence of complications [6, 20, 33, 34]. However, even with inclusion of gender and diabetic complications in the model, frequency of hyperglycemic symptoms was associated with lower health-utility scores. The magnitude of the differences in health-utility scores in patients with and without hyperglycemic symptoms was small compared to the magnitude of the differences in patients with and without diabetic complications and may be clinically less important. However, having $>4$ episodes of hyperglycemic symptoms over the past month was associated with clinically meaningful reductions in health-utility scores of $0.036-0.072$ in patients with type- 2 diabetes and $0.040-0.080$ in patients with type- 1 diabetes. The lack of a significant association between hypoglycemia and QWB-SA-derived health-utility scores might be explained by the fact that hypoglycemia is an infrequent, brief, and usually self-limited event that might affect QoL less than persistent hyperglycemia.

Our study has some limitations. First, because we analyzed self-reported measures of glycemia, recall bias may be present. Second, because our study was cross-sectional, we cannot establish a temporal relationship between exposure and outcome. Finally, the association between the frequency of hyperglycemic or hypoglycemic symptoms and QWB-SA symptoms (Table 2) might be confounded by depressive symptoms. Despite these limitations, we found a clinically meaningful negative association between self-reported frequency of hyperglycemic symptoms in type-1 and type-2 diabetic patients and QWB-SAderived health-utility scores. The association existed for frequency of hyperglycemic symptoms alone and for frequency of hyperglycemic symptoms after adjusting for gender and diabetic complications. We also found a small negative association between the frequency of hypoglycemic symptoms in type- 2 diabetes patients and health-utility scores, but no association with HbA1c. These results suggest that the QWB-SAderived health-utility score may be an appropriate measure to assess the health burden of hyperglycemia. Prospective studies that include repeated measurements of both health-utility scores and glycemia are needed.

\section{References}

1. Rubin RR, Peyrot M. Quality of life in diabetes. Diabetes Metab Res Rev 1999; 15: 205-218.

2. Ahroni JH, Boyko EJ, Davignon DR, Pecoraro RE. The health and functional status of veterans with diabetes. Diabetes Care 1994; 17: 318-321.

3. Klein BE, Klein R, Moss SE. Self-rated health and diabetes of long duration. The Wisconsin Epidemiologic Study of Diabetic Retinopathy. Diabetes Care 1998; 21: 236-240.

4. Wikblad K, Leksell J, Wibell L. Health-related quality of life in relation to metabolic control and late complications in patients with insulin dependent diabetes mellitus. Qual Life Res 1996; 5: 123-130.

5. Koopmanschap M. Coping with type II diabetes: The patient's perspective. Diabetologia 2002; 45: S18-22.

6. Coffey TA, Brandle M, Zhou H, et al. Valuing health-related quality of life in diabetes mellitus. Diabetes Care 2002; 25: 2238-2243.

7. Kaplan RM, Ganiats TG, Sieber WJ, Anderson JP. The quality of well-being scale: Critical similarities and differences with SF-36. Int J Qual Health Care 1998; 10: 509-520.

8. Kaplan RM, Sieber WJ, Ganiats TG. The Quality of WellBeing Scale. Comparison of the interviewer-administered version with a self-administered questionnaire. Psychol Health 1997; 12: 783-791.

9. Haddix A, Teutsch S, Shaffer P, et al. (eds), A Practical Guide to Prevention Effectiveness: Decision and Economic Analyses. Centers for Disease Control and Prevention, Department of Health and Human Services, Public Health Service, 1993: 123-133.

10. Lenert L, Kaplan RM. Validity and interpretation of preference-based measures of health-related quality of life. Med Care 2000; 38(9 Suppl): 138-150. 
11. Gold MR, Patrick DL, Torrance GW, et al. Identifying and valuing outcomes. In: Gold MR, Siegel JE, Russell LB, Weinstein MC (eds), Cost-effectiveness in Health and Medicine. New York: Oxford University Press, 1996: 82134.

12. Erickson P, Kendall EA, Anderson JP, Kaplan RM. Using composite health status measures to assess the nation's health. Med Care 1989; 27(3 Suppl): S66-S76.

13. Kaplan RM. Hippocratic Predicament: Affordability, Access, and Accountability in Health Care. San Diego: Academic Press, 1993.

14. Balaban DJ, Sagi PC, Goldfarb NI, Nettler S. Weights for scoring the quality of well-being instrument among rheumatoid arthritics: A comparison to the general population weights. Med Care 1986; 24: 973-980.

15. Orenstein DM, Nixon PA, Ross EA, Kaplan RM. The quality of well-being in cystic fibrosis. Chest 1989; 95 : 344 347.

16. Orenstein DM, Pattishal EN, Nixon PA, et al. Quality of well-being before and after antibiotic treatment of pulmonary exacerbation in patients with cystic fibrosis. Chest 1990; 98: 1081-1084.

17. Kaplan RM, Hartwell SL, Wilson DK, Wallace JP. Effects of diet and exercise interventions on control and quality of life in non-insulin-dependent diabetes mellitus. J Gen Intern Med 1987; 2: 220-228.

18. Kaplan RM, Anderson JP, Patterson TL, et al. Validity of the quality of well-being scale for persons with human immunodeficiency virus infection. Psychosomatic Med 1995; 57: 138-157.

19. Bombardier C, Ware J, Russell IJ, et al. and the Auranofin Cooperating Group: Auranofin therapy and quality of life in patients with rheumatoid arthritis. Results of a Multicenter Trial. Am J Med 1986; 81: 565-578.

20. Anderson RM, Fitzgerald JT, Wisdom K, et al. A comparison of global versus disease-specific quality-of-life measures in patients with NIDDM. Diabetes Care 1997; 20: 299-305.

21. Fitzgerald JT, Davis WK, Connell CM, et al. Development and validation of the Diabetes Care Profile. Eval Health Profess 1996; 19: 208-230.

22. Grootenhuis PA, Snoek FJ, Heine RJ, Bouter LM. Development of a type-2 diabetes symptom checklist: A measure of symptom severity. Diabetic Med 1994; 11: 253261.

23. Testa MA, Simonson DC. Health economic benefits and quality of life during improved glycemic control in patients with type-2 diabetes mellitus: A randomized, controlled, double-blind trial. JAMA 1998; 280: 1490-1496.
24. Katz MH. Multivariable Analysis: A Practical Guide for Clinicians. Cambridge, UK: Cambridge University Press, 1999.

25. Kleinbaum DG, Kupper LL, Muller KE. Applied Regression Analysis and other Multivariable Methods. 2nd ed. Boston, Massachusetts: PWS-Kent, 1988.

26. Guyatt GH, Veldhuyzen Van Zanten SJ, et al. Measuring quality of life in clinical trials: A taxonomy and review. CMAJ 1989; 140: 1441-1448.

27. Boyer JG, Earp JA. The development of an instrument for assessing the quality of life of people with diabetes: Diabetes-39. Med Care 1997; 35: 440-453.

28. Weinberger M, Kirkman MS, Samsa GP, et al. The relationship between glycemic control and health-related quality of life in patients with non-insulin-dependent diabetes mellitus. Med Care 1994; 32: 1173-1181.

29. Hanestad BR, Graue M. To maintain quality of life and satisfactory metabolic control in type II diabetes patients. Qual Life Res 1995; 4: 436-437.

30. Bagne CA, Luscombe FA, Damiano A. Relationships between glycemic control, diabetes-related symptoms and SF36 scales scores in patients with non-insulin dependent diabetes mellitus. Qual Life Res 1995; 4: 392-393.

31. Glasgow RE, Ruggiero L, Eakin EG, et al. Quality of life and associated characteristics in a large national sample of adults with diabetes. Diabetes Care 1997; 20: 562567.

32. Petterson T, Lee $\mathrm{P}$, Hollis $\mathrm{S}$, et al. Well-being and treatment satisfaction in older people with diabetes. Diabetes Care 1998; 21: 930-935.

33. Peyrot M, Rubin RR. Levels and risks of depression and anxiety symptomatology among diabetic adults. Diabetes Care 1997; 20: 585-590.

34. Jacobson AM, de Groot M, Samson JA. The evaluation of two measures of quality of life in patients with type I and type II diabetes. Diabetes Care 1994; 17: 267-274.

35. Trief PM, Grant W, Elbert K, Weinstock RS. Family environment, glycemic control, with the psychosocial adaptation of adults and diabetes. Diabetes Care 1998; 21: 241245 .

Address for correspondence: William H. Herman, University of Michigan Health System, Division of Endocrinology and Metabolism, 1500 East Medical Center Drive, 3920 Taubman Center, Ann Arbor, MI 48109-0354, USA

Phone: +1-734-936-8279; Fax: +1-734-936-9240

E-mail:wherman@umich.edu 